OPEN ACCESS

Edited by:

Kerry-Ann F. O'Grady,

Queensland University of

Technology, Australia

Reviewed by:

Danilo Buonsenso,

Catholic University of the Sacred

Heart, Italy

Antonio Gatto,

Agostino Gemelli University Polyclinic

(IRCCS), Italy

*Correspondence:

Alireza Tahamtan

dr.tahamtan@goums.ac.ir;

Alireza.tmn@gmail.com

Britt Nakstad

britt.nakstad@medisin.uio.no

Specialty section:

This article was submitted to

Pediatric Pulmonology,

a section of the journal

Frontiers in Pediatrics

Received: 03 November 2021 Accepted: 21 December 2021

Published: 13 January 2022

Citation:

Najafinejad M, Cheraghali F,

Aghcheli B, Rajabi A, Barati L, Naziri H, Gharib MH, Tabarraei A, Nakstad B and Tahamtan A (2022)

COVID-19 in Pediatrics: Demographic, Clinical, Laboratory, and Radiological Characteristics of Infected Patients With SARS-CoV-2.

Front. Pediatr. 9:808187.

doi: 10.3389/fped.2021.808187

\section{COVID-19 in Pediatrics: Demographic, Clinical, Laboratory, and Radiological Characteristics of Infected Patients With SARS-CoV-2}

\begin{abstract}
Maryam Najafinejad ${ }^{1}$, Fatemeh Cheraghali ${ }^{1}$, Bahman Aghcheli ${ }^{2}$, Abdolhalim Rajabi ${ }^{3}$, Leila Barati ${ }^{1}$, Hamed Naziri ${ }^{4}$, Mohammad Hadi Gharib ${ }^{5}$, Alijan Tabarraei ${ }^{2}$, Britt Nakstad ${ }^{6,7 *}$ and Alireza Tahamtan ${ }^{2,8 *}$

1 Department of Pediatrics, School of Medicine, Taleghani Children's Hospital, Golestan University of Medical Sciences, Gorgan, Iran, ${ }^{2}$ Department of Microbiology, School of Medicine, Golestan University of Medical Sciences, Gorgan, Iran, ${ }^{3}$ Department of Biostatistics and Epidemiology, Faculty of Health, Environmental Health Research Center, Golestan University of Medical Sciences, Gorgan, Iran, ${ }^{4}$ Department of Microbiology, School of Medicine, Guilan University of Medical Sciences, Rasht, Iran, ${ }^{5}$ Department of Radiology, School of Medicine, 5th Azar Hospital, Golestan University of Medical Sciences, Gorgan, Iran, ${ }^{6}$ Division of Paediatric and Adolescent Medicine, University of Oslo, Oslo, Norway, ${ }^{7}$ Department of Paediatrics and Adolescent Health, University of Botswana, Gaborone, Botswana, ${ }^{8}$ Infectious Diseases Research Centre, Golestan University of Medical Sciences, Gorgan, Iran
\end{abstract}

The COVID-19 disease usually leads to mild infectious disease in children, but some develop serious complications. Here, we describe the characteristics of children with COVID-19 in northern Iran, the Golestan province. Ninety-one confirmed cases were enrolled in the study, aged 0-18 years. Demographic, clinical, comorbidity, laboratory, and radiological data were compared based on the disease severity (admitted to intensive care unit (ICU) or not) and disease outcome (recovered or deceased). Sixteen (17.5\%) cases were hospitalized in ICU, and 8/91 (8.8\%) deceased. Fever and cough were the most common clinical symptoms. Among all symptoms notified there were no significant differences between severe and milder cases, or between those who deceased and recovered. Failure to thrive $(\mathrm{FTT})$, malignant disease and neurological disease were significantly more prevalent in severe cases as was frequently reported comorbidities. Laterality, ground-glass opacity, and lung consolidation were the most common findings in chest computed tomography. The data confirms that the COVID-19 disease has various presentations in children, and clinical, laboratory, and radiological findings may help predict the development of severe forms of COVID-19 among children.

Keywords: children, COVID-19, SARS-CoV-2, Iran, Gorgan

\section{INTRODUCTION}

A sudden outbreak of the novel severe acute respiratory syndrome coronavirus 2 (SARS-CoV2) was identified in China at the end of 2019 and then spread worldwide (1). The World Health Organization (WHO) declared this a pandemic, the COVID-19 disease (2), a complicated respiratory disease that became a major global health threat (3). As of November 2th 2021, more than 247 million patients with COVID-19 have been confirmed globally, and more than 5.9 million confirmed cases have been reported in Iran. 
Human beings are susceptible to the SARS-CoV-2 infection, though the clinical course and disease outcome vary from case to case (4). Patients with underlying diseases such as diabetes, hypertension, cardiovascular disease, and chronic bronchitis are the most affected and associated with much higher case-fatality rates (5). The severity of COVID-19 depends on a complicated interaction between the host, virus, and environment, leading to different clinical courses and disease outcomes $(6,7)$. Importantly, reported disease burden and case fatality rates differ considerably among different age groups (8, 9). In children, COVID-19 usually leads to a mild infectious disease, although some develop serious complications like the multisystem inflammatory syndrome (MIS-C) $(10,11)$.

The first reports on COVID disease indicated that children usually present with a mild or asymptomatic infection and are less prone to severe COVID-19 (12), maybe due to their staying at home during the pandemic with less contact with the source of infection, and a developing immune system with more pulmonary stem cells that can repair the injured cells (7). Some studies reported non-specific symptoms (13-15). Moreover, there is not enough data to determine the exact characteristics of SARS-CoV-2 infection in children. This paper reports demographic, clinical, laboratory, and radiological characteristics of pediatric COVID-19 cases admitted in Taleghani Children Hospital in Gorgan, north of Iran, and aims to define factors that may help predict the development of severe forms of COVID-19 among children, at least in northern Iran.

\section{METHODS}

This retrospective study was conducted on data collected from children hospitalized during March 2020 and February 2021 in a referral hospital for pediatric COVID-19, Taleghani Children Hospital, Gorgan, in the northern region of Iran. A total of 91 confirmed COVID-19 patients (aged 0-18 years) were enrolled in the study. All patients had been confirmed positive by reverse transcriptase Real-time PCR (rRT-PCR) targeting the SARS-CoV-2 nucleoprotein (N) and ORF1ab genes according to the Iranian national COVID-19 diagnostic protocol. Demographic, clinical, and laboratory data were collected from the patients' case reports. The available radiological findings [chest computed tomography (CT) images] were extracted from electronic medical records and were reviewed by a specialist. Patients were characterized and divided based on the following: disease severity [admitted to intensive care unit (ICU) or not] and disease outcome (recovered or deceased). The study was approved by the Ethics Committee of Golestan University of Medical Sciences (IR.GOUMS.REC.1400.142).

Statistical analyses were performed using SPSS version 25.0 (IBM Corp., Armonk, NY, USA). The continuous variables were

\footnotetext{
Abbreviations: SARS-CoV-2, Severe acute respiratory syndrome coronavirus 2; WHO, World Health Organization; MIS-C, Multisystem inflammatory syndrome; rRT-PCR, Real-time PCR; CT, Computed tomography; ICU, Intensive care unit; FTT, Failure-to-Thrive; ARDS, Acute respiratory distress syndrome; PT, Prothrombin time; CPK, Creatine phosphokinase; LDH, Lactate dehydrogenase; WBC, White blood cells; AST, Aspartate aminotransferase; CRP, C-reactive protein.
}

presented as median (range), and the classification variables were presented in number (\%). We performed the chi-square and Mann-Whitney tests to compare the continuous and classification variables between groups (ICU vs. non-ICU and recovered vs. deceased patients). $P<0.05$ were considered statistically significant. As multiple hypotheses were tested, the likelihood of type I error increased. Data are available for Bonferroni-correction analyses for each individual hypothesis and presented in Tables.

\section{RESULTS}

Between March 14th 2020 and February 24th 2021, 91 children with confirmed COVID-19 (laboratory-confirmed cases) were admitted to the Taleghani Pediatrics Hospital in Gorgan city. Of 91 patients, $16(17.5 \%)$ and $75(82.5 \%)$ cases were hospitalized in ICU and non-ICU wards, respectively. Of these, 83 (91.2\%) and $8(8.8 \%)$ patients had recovered and deceased outcomes, respectively. Of all cases, $55(60.4 \%)$ and 36 (39.6\%) were males and females, respectively. The median age of all patients was 32 months (IQR 11-91). The patients were divided into different age groups, 33/91 were infants aged $<1$ year. No differences were observed in demographic data between groups. Details of demographic data are presented in Table $\mathbf{1 .}$

Clinical symptoms apparent in the patient and signs that the physician perceived such as fever (68.13\%) and cough $(61.54 \%)$ were most frequently reported. There was a significant difference in dyspnea reported between recovered and deceased groups, as well as lethargy between the severe cases admitted to ICU vs. nonICU cases of mild-to-moderate disease. Moreover, differences were found in immunodeficiency and neurological diseases between ICU and non-ICU cases. There were comorbidities such as Failure-to-Thrive (FTT), immunodeficiency, neurological diseases, and acute cardiac injury in both recovered and deceased groups. Totally, there were 8 deaths among our cases. The first who died of pediatric COVID-19 in our department was a 12 year old female with a history of dyspnea and aortic valve stenosis. Other expired female aged 5 months suffered severe failure-to-thrive (FTT). Two male fatal cases showed primary immunodeficiency disease. Another 2 male fatal cases with COVID-19 disease suffered from metastatic brain cancer and were immunosuppressed on chemotherapy treatment. One other male fatal case had gastrostomy feeding in cerebral palsy.

The underlying cause was unclear, anticipated as one several possible causes. Children aged $<1$ year were the prominent group of COVID-19 patients (33/91) of whom 3/33 deceased and $7 / 33$ were severely ill and admitted to ICU. This infant group contributed to $3 / 8$ of all who demised. The other major contributing group were children $>6$ years of whom 4/29 were admitted to ICU and 2 of these deceased. Four patients had co-infection, 2 with bacterial, Haemophilus influenza, and tuberculosis (TB), respectively. One was HIV positive and the fourth was seropositive for hydatid cyst. None of the co-infected patients died. Intubation was performed in about $10 \%$ of cases, all were ICU admitted. A significant number of deceased and ICU cases had been using corticosteroids. All acute respiratory distress 
TABLE 1 | Demographic data of pediatric COVID-19 cases.

\begin{tabular}{|c|c|c|c|c|c|c|c|}
\hline \multirow[t]{2}{*}{ Variables } & \multirow[t]{2}{*}{ Total } & \multicolumn{2}{|c|}{ Outcome } & \multirow[t]{2}{*}{$P$-value } & \multicolumn{2}{|c|}{ Severity } & \multirow[t]{2}{*}{$P$-value } \\
\hline & & Deceased & Recovered & & ICU & Non-ICU & \\
\hline Number (\%) & $91(100)$ & $8(8.8)$ & $83(91.2)$ & & $16(17.5)$ & 75 (82.5) & - \\
\hline \multicolumn{8}{|l|}{ Sex } \\
\hline Male (\%) & $55(60.4)$ & $5(62.5)$ & $50(60.2)$ & 0.90 & $10(62.5)$ & $45(60)$ & 0.85 \\
\hline Female (\%) & $36(39.6)$ & $3(37.5)$ & $33(39.8)$ & & $6(37.5)$ & $30(40)$ & \\
\hline Age (Months, Median, IQR) & $32(11-91)$ & $27(12-114)$ & $32(11-91)$ & 0.59 & $21(12-100.5)$ & $34(11-91)$ & 0.85 \\
\hline \multicolumn{8}{|l|}{ Age groups (Months) (\%) } \\
\hline$\leq 1$ & $2(2.20)$ & $0(0)$ & $2(2.41)$ & 0.96 & $0(0)$ & $2(2.7)$ & 0.63 \\
\hline $2-12$ & $31(34.06)$ & $3(37.5)$ & 28 (33.73) & & $7(43.75)$ & $24(32.43)$ & \\
\hline $13-36$ & $17(18.68)$ & $2(25)$ & 15 (18.08) & & $4(25)$ & $12(16.23)$ & \\
\hline $37-72$ & $12(13.19)$ & $1(12.5)$ & $11(13.25)$ & & $1(6.25)$ & $11(14.86)$ & \\
\hline$>72$ & $29(31.87)$ & $2(25)$ & 27 (32.53) & & $4(25)$ & 25 (33.78) & \\
\hline
\end{tabular}

ICU, Intensive Care Unit; IQR, Interquartile Range; All deceased were admitted to ICU.

syndrome (ARDS) cases were in deceased and ICU groups. Detailed information on age groups, deceased vs. recovered, ICU admitted with severe disease is given in Table 2.

Laboratory data were statistically analyzed among all groups. The result revealed significant differences in parameters such as prothrombin time (PT), creatine phosphokinase (CPK), and lactate dehydrogenase (LDH) between recovered and deceased groups, and for white blood cells (WBC), PT, CPK, LDH, and aspartate aminotransferase (AST) between ICU and non-ICU groups. About $21 \%$ of all cases had lymphopenia, and $50 \%$ had elevated C-reactive protein (CRP) $(\geq+1)$, though there was no significant difference between groups. Details of laboratory data are presented in Table 3.

Of all patients, 22 cases had chest CT images available. The type and size of the pathological findings were used for classification. Laterality, ground-glass opacity, and lung consolidation were the most common findings in chest CT. However, significant differences were found in crazy paving pattern and pleural effusion between recovered and deceased groups. Details of radiological findings are presented in Table 4.

\section{DISCUSSION}

This is a retrospective study on the clinical features of pediatric patients with COVID-19 from Iran. The WHO guidelines and the Iranian national recommendation for COVID-19 were considered for case identification (16). The percentage of deaths in COVID-19-associated pediatric patients in this study is dramatically higher than in other studies which reported no or rare fatality among children (17-19). The reasons for this may be the presence of children with comorbidities or a higher number of samples in our study compared with other studies. Consistent with previous studies in adults ( 7,20$)$, the findings showed that male children tended to be more susceptible to COVID-19. Although no statistical difference observed between gender in this study, a reduced vulnerability of females to the infection could possibly be genetic, hormonal, and immunological differences or higher expression levels of ACE2 in males (7). Most confirmed and severe cases of COVID-19 were observed in children aged $<1$ year which was similar to previous reports (21). This may be because they cannot wear masks and require specific protective measures.

Literature indicates that children may be asymptomatic or have mild or no clinical symptoms compared with adults (21, 22). We included hospitalized children and found similar to previous studies, that fever and cough were the predominant clinical characteristics of COVID-19 among children (17, 23), followed by dyspnea (29\%), lethargy and weakness (26\%), and vomiting (23\%). Gastrointestinal manifestations included anorexia, nausea, vomiting, and diarrhea that could develop into more severe outcomes in pediatric patients (24). We found gastrointestinal symptoms to be incredibly higher than in adults in previous studies $(25,26)$. A correlation between COVID-19 disease and skin rashes has been described by Guan et al. (27) and 3 cases were previously reported by Duramaz et al. in pediatric patients with COVID-19 (28). In line with this we found cutaneous manifestations in six children. The role of COVID-19 in the appearance of skin rashes in pediatric patients is controversial and more investigations are needed to conclude if skin rash is a clinical sign of COVID19 disease.

Comorbidities may increase the risk of developing severe and fatal pediatric COVID-19 disease $(29,30)$. In this study, as previously reported by Ogimi et al. (31), children younger than seven years with immunosuppressive diseases or underlying medical conditions were more vulnerable to COVID-19. In our study, comorbidities such as FTT and immunodeficiency were major risk factors for death. We found a significant difference in the outcome of COVID19 disease among children with and without FTT. Also, similar to previous studies, there was a strong correlation between comorbidities and illness severity and mortality (32). 
TABLE 2 | Clinical data of pediatric COVID-19 cases.

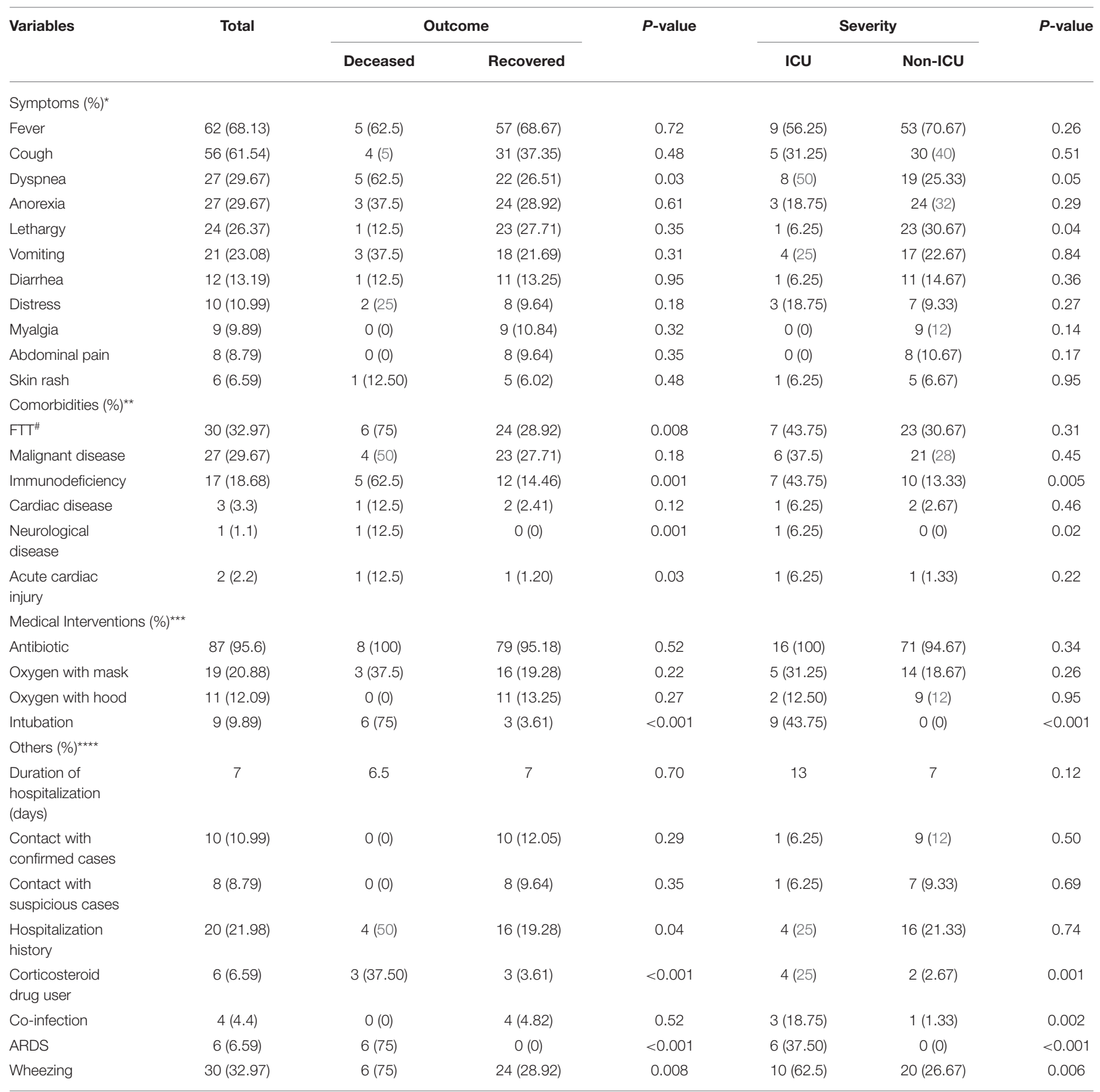

ICU, Intensive Care Unit; FIT, Failure To Thrive; ARDS, Acute Respiratory Distress Syndrome.

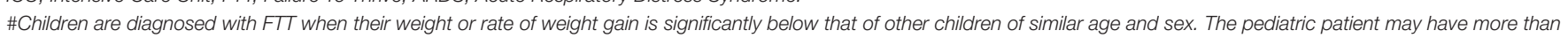
one comorbidity.

${ }^{*}$ The threshold for significance is Bonferroni-corrected from $P<0.05$ to $P<0.004$.

**The threshold for significance is Bonferroni-corrected from $P<0.05$ to $P<0.008$.

${ }^{\star \star \star}$ The threshold for significance is Bonferroni-corrected from $P<0.05$ to $P<0.01$.

${ }^{\star \star \star \star}$ The threshold for significance is Bonferroni-corrected from $P<0.05$ to $P<0.006$.

Our findings showed that immunodeficiency, neurological disease, and acute cardiac injury were comorbidities associated with developing severe disease and a higher risk of fatal outcome. Importantly, neurological manifestations were noted as presenting symptom or complication in two our cases.
One patient presented transverse myelitis and another was diagnosed with viral encephalitis with possible parenchymal hemorrhagic components.

It has been revealed that intubation does not affect infected patients' death rate or illness severity (33). In this study, 6 
TABLE 3 | Laboratory data of pediatric COVID-19 cases.

\begin{tabular}{|c|c|c|c|c|c|c|c|}
\hline \multirow[t]{2}{*}{ Variables } & \multirow[t]{2}{*}{ Total (Median, IQR) } & \multicolumn{2}{|c|}{ Outcome } & \multirow[t]{2}{*}{$P$-value } & \multicolumn{2}{|c|}{ Severity } & \multirow[t]{2}{*}{$P$-value } \\
\hline & & $\begin{array}{c}\text { Deceased } \\
\text { (Median, IQR) }\end{array}$ & $\begin{array}{c}\text { Recovered } \\
\text { (Median, IQR) }\end{array}$ & & $\begin{array}{c}\text { ICU } \\
\text { (Median, IQR) }\end{array}$ & $\begin{array}{c}\text { Non-ICU } \\
\text { (Median, IQR) }\end{array}$ & \\
\hline WBC $(\mu / l)$ & $10,700(6,500-16,000)$ & $\begin{array}{c}15,950 \\
(7,150-23,700)\end{array}$ & $\begin{array}{c}10,700 \\
(6,300-14,800)\end{array}$ & 0.16 & $\begin{array}{c}17,850 \\
(9,600-23,000)\end{array}$ & $\begin{array}{c}10,100 \\
(6,100-13,600)\end{array}$ & 0.004 \\
\hline PMN (\%) & $60(41.5-73.5)$ & $62.5(45-84)$ & $60(40-72)$ & 0.47 & $66.5(51-83.5)$ & $59(40-70)$ & 0.09 \\
\hline Lymph (\%) & 39 (20.5-55) & $35(16-55)$ & $39(21.5-55)$ & 0.59 & $25(16.5-54)$ & $39(24.5-56)$ & 0.16 \\
\hline $\mathrm{HB}(\mathrm{mg} / \mathrm{dl})$ & 10.85 (9.50-12.60) & $\begin{array}{c}10.40 \\
(8.35-11.20)\end{array}$ & $11(9.50-12.70)$ & 0.15 & $11.2(9.40-12.70)$ & $\begin{array}{c}10.85 \\
(9.50-12.60)\end{array}$ & 0.94 \\
\hline $\operatorname{PLT}\left(\mathrm{mm}^{3} / \mu \mathrm{l}\right)$ & $185,000(476-300,000)$ & $\begin{array}{c}107,000 \\
(64,000-328,000)\end{array}$ & $\begin{array}{c}191,500 \\
(404-299,500)\end{array}$ & 0.70 & $\begin{array}{c}107,000 \\
(62,000-292,000)\end{array}$ & $\begin{array}{c}191,500 \\
(404-308,500)\end{array}$ & 0.87 \\
\hline ESR (mm/h) & $20(9-41)$ & $15(6-36)$ & $20(9-43.5)$ & 0.50 & $25(9-35)$ & $19(9-46)$ & 0.71 \\
\hline BUN (mg/dl) & $12(9-14)$ & $12(10.5-16.5)$ & $11(9-14)$ & 0.43 & $11(9-13)$ & $12(9-14)$ & 0.59 \\
\hline Creatinine (mg/dl) & $0.6(0.5-0.6)$ & $0.6(0.55-0.7)$ & $0.6(0.5-0.60)$ & 0.28 & $0.6(0.50-0.60)$ & $0.59(0.5-0.6)$ & 0.61 \\
\hline $\mathrm{K}(\mathrm{mEq} / \mathrm{L})$ & $4.2(4-4.8)$ & 4.25 (3.65-4.7) & $4.20(4-4.80)$ & 0.77 & $4.20(4.10-4.70)$ & $4.25(4-4.80)$ & 0.58 \\
\hline $\mathrm{Na}(\mathrm{mEq} / \mathrm{L})$ & $140(137-143)$ & $140(135-143)$ & $140(137-143)$ & 0.82 & $140.5(138-143)$ & $140(137-142)$ & 0.26 \\
\hline $\mathrm{Ca}(\mathrm{mg} / \mathrm{dl})$ & 8.7 (8.3-9.6) & $8.3(7.80-8.40)$ & 9.05 (8.5-9.6) & 0.20 & $8.40(7.80-10)$ & 9.05 (8.50-9.55) & 0.42 \\
\hline INR (second) & $1.2(1-1.40)$ & $1.70(1.40-1.80)$ & $1.10(1-1.30)$ & 0.04 & $1.40(1.10-1.80)$ & $1.15(1-1.30)$ & 0.26 \\
\hline PT (second) & $14.10(13.20-15.20)$ & $\begin{array}{c}17.35 \\
(15.20-18.30)\end{array}$ & $13.80(13-14.60)$ & 0.006 & $\begin{array}{c}15.85 \\
(13.90-18.25)\end{array}$ & $13.80(13-14.60)$ & 0.02 \\
\hline PTT (second) & $40(38-46.5)$ & $49.5(37-70)$ & $40(39-40)$ & 0.21 & 46.5 (39.5-60.50) & $39.50(38-40)$ & 0.07 \\
\hline CPK (U/L) & $144(82-363)$ & $938(422-1,121)$ & 125.5 (82-226.5) & 0.01 & $570(173-1,121)$ & 106.5 (81-207.5) & 0.004 \\
\hline LDH (U/L) & 657 (559-883) & $1366(883-1,887)$ & $\begin{array}{c}650.5 \\
(529.5-840.5)\end{array}$ & 0.006 & $\begin{array}{c}1124.5 \\
(731.5-1917.5)\end{array}$ & $651(547-822)$ & 0.01 \\
\hline ALT (IU/L) & $36(20-60)$ & 56 (26-291) & 35 (19-58) & 0.12 & $52.5(26-95)$ & $35(19-51)$ & 0.13 \\
\hline AST (IU/L) & $50(37-71)$ & $62(49-333)$ & $47(35-71)$ & 0.18 & 70 (43.5-166.5) & $46(35-60)$ & 0.04 \\
\hline $\begin{array}{l}\text { Abnormal urine } \\
\text { analysis, N (\%) }\end{array}$ & $6(6.59)$ & $1(12.50)$ & $5(6.02)$ & 0.48 & $1(6.25)$ & $5(6.67)$ & 0.95 \\
\hline $\begin{array}{l}\text { Lymphopenia, } \\
\text { N (\%) }\end{array}$ & 19 (20.88) & $3(37.50)$ & 16 (19.28) & 0.22 & $5(31.25)$ & $14(18.67)$ & 0.26 \\
\hline $\begin{array}{l}{ }^{*} \mathrm{CRP} \text { positive, } \\
\mathrm{N}(\%)\end{array}$ & $45(49.5)$ & $4(50)$ & $41(49.4)$ & 0.97 & $9(56.3)$ & $36(48)$ & 0.54 \\
\hline
\end{tabular}

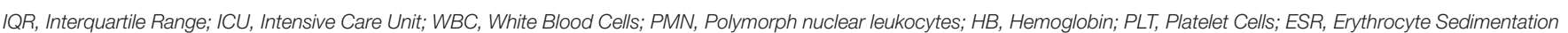

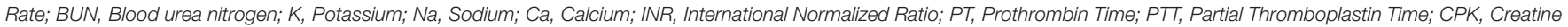
Phosphokinase; LDH, Lactate Dehydrogenase; ALT, Alanine Aminotransferase; AST, Aspartate Aminotransferase; CRP, C-reactive protein.

*One plus (+1) and higher are considered as CRP positive (a value of 8-10 $\mathrm{mg} / \mathrm{L}$ or lower is normal).

The threshold for significance is Bonferroni-corrected from $P<0.05$ to $P<0.002$.

(75\%) deceased and 9 (43.7\%) ICU patients needed intubation and ventilatory support, consistent with results in adults (34). Similar to Soltani et al., a study from Iran, only $10(10.9 \%)$ of patients had a history of contact with confirmed cases (17). However, these findings were extremely different from two other studies, which reported that $90 \%$ had close contacts with confirmed patients $(12,35)$. ARDS is a life threatening lung injury, breathing becomes difficult with poor oxygenation, and ARDS is associated with poor outcomes or an increased risk for fatality in children hospitalized with SARS-CoV-2 infection (36). In our pediatric cohort 6/91 (6.59\%) presented with ARDS and needed ventilatory support, in contrast to Khoshnood et al. (37) where almost $23 \%$ of adults patients showed ARDS. The median number of hospitalized days was seven, less than previously reported in adults (38). Factors such as discharge and hospitalization criteria in different countries may justify this difference.
Despite the WHO recommendation (39), which states that antibiotic treatment is not necessary for mild/moderate COVID19 disease, antibiotics were prescribed for most patients (95.6\%) in this study, with no differences between groups. As shown in Table 2, only 2 patients proved to be co-infected with bacteria species, Haemophilus influenzae, and tuberculosis, respectively. One patient was HIV positive and the fourth was seropositive for hydatid cyst. A total of 8/91 COVID-19 infected children died, and all had co-morbidities, with immune deficiency (primary or treatment-induced) being the most important co-morbidity associated with mortality. In the beginning of the pandemic guidelines for treatment and healthcare of diseased children and surveillance systems were not in place in Iran leading to non-uniform treatment of the diseased children. Monitoring of trends of disease activity among children, and following up with important steps to mitigate disease such as closing schools and kindergartens came later in the pandemic. 
TABLE 4 | Radiological findings of pediatric COVID-19 cases.

\begin{tabular}{|c|c|c|c|c|c|c|c|}
\hline \multirow[t]{2}{*}{ Variables } & \multirow[t]{2}{*}{ Total (N:91) } & \multicolumn{2}{|c|}{ Outcome } & \multirow[t]{2}{*}{$P$-value } & \multicolumn{2}{|c|}{ Severity } & \multirow[t]{2}{*}{$P$-value } \\
\hline & & Deceased $(n=8)$ & Recovered $(n=83)$ & & $\operatorname{ICU}(n=16)$ & Non-ICU $(n=75)$ & \\
\hline Chest CT $(\%)^{\star}$ & 22 & 2 & 20 & - & 3 & 19 & - \\
\hline Laterality & $22(100)$ & $2(9.09)$ & $20(90.91)$ & 0.995 & $3(13.63)$ & 19 (86.37) & 0.577 \\
\hline $\begin{array}{l}\text { Ground-glass } \\
\text { opacity }\end{array}$ & $22(100)$ & 2 (9.09) & $20(90.91)$ & 0.955 & $3(13.63)$ & $19(86.37)$ & 0.577 \\
\hline Lung consolidation & $14(63.64)$ & $2(14.28)$ & $12(85.72)$ & 0.430 & $3(21.42)$ & $11(78.58)$ & 0.681 \\
\hline $\begin{array}{l}\text { Reticular nodular } \\
\text { opacity }\end{array}$ & 7 (31.81) & 1 (14.2) & $6(85.8)$ & 0.593 & 1 (14.2) & $6(85.8)$ & 0.812 \\
\hline $\begin{array}{l}\text { Crazy paving } \\
\text { pattern }\end{array}$ & $2(9.09)$ & $1(50)$ & $1(50)$ & 0.037 & $1(50)$ & $1(50)$ & 0.223 \\
\hline Pleural effusion & 2 (9.09) & $1(50)$ & $1(50)$ & 0.037 & $1(50)$ & $1(50)$ & 0.223 \\
\hline Cardiomegaly & $1(4.54)$ & $0(0)$ & $1(100)$ & 0.755 & $0(0)$ & $1(100)$ & 0.642 \\
\hline $\begin{array}{l}\text { Lung lobar } \\
\text { (segmental) } \\
\text { distribution\# }\end{array}$ & $21(95.46)$ & $2(9.5)$ & 19 (90.5) & 0.738 & $3(14.28)$ & 18 (85.72) & 0.371 \\
\hline $1-2$ & $4(19.04)$ & $0(0)$ & $4(100)$ & & $0(0)$ & $4(100)$ & \\
\hline $3-4$ & 7 (33.35) & $1(14.28)$ & $6(85.72)$ & & $2(28.57)$ & $5(71.43)$ & \\
\hline 5 & $10(47.61)$ & $1(10)$ & $9(90)$ & & $1(10)$ & $9(90)$ & \\
\hline Lung involvement & $22(100)$ & 2 (9.09) & $20(90.91)$ & 0.194 & $3(13.63)$ & 19 (86.37) & 0.425 \\
\hline $25 \%$ & $6(27.28)$ & $0(0)$ & $6(100)$ & & 1 (33.34) & 5 (66.66) & \\
\hline $50 \%$ & $8(36.37)$ & $0(0)$ & $8(100)$ & & $0(0)$ & $8(100)$ & \\
\hline $75 \%$ & $7(31.80)$ & $2(28.57)$ & $5(71.43)$ & & $2(6.66)$ & 5 (93.34) & \\
\hline $100 \%$ & $1(4.55)$ & $0(0)$ & $1(100)$ & & $0(0)$ & $1(100)$ & \\
\hline
\end{tabular}

ICU, Intensive Care Unit; CT, Computed Tomography.

Findings are characterized and reviewed by a specialist in radiology.

\#Lung lobar (segmental) distribution means the number of involved lobes.

*The threshold for significance is Bonferroni-corrected from $P<0.05$ to $P<0.005$.

Prolonged PT and elevated PT/INR (international normalized ratio) were detected significantly more often in deceased and ICU admitted children. In line with previous studies in adults and children $(40,41)$, the correlation between coagulation irregularities and the disease severity was confirmed, indicating that liver dysfunction can be used as a marker for predicting the severity of COVID-19 in children (42). In this study, a tendency for increased severity was seen among cases with elevated AST, similar to results from a meta-analysis (43). ICU admitted and deceased patients had a significantly higher level of CPK compared with non-ICU and recovered patients, respectively, in line with other and systematic literature reviews $(44,45)$. It has been well-documented that elevated CPK level is associated with the increased likelihood of a poor outcome (44). Adult patients with severe symptoms have higher $\mathrm{LDH}$ as an indicator for tissue damage (46). Similarly, we prove higher LDH levels in deceased vs. recovered children as well as ICU admitted vs. milder affected children.

CRP is used to assess inflammation in the body, and its role in combating infection has been determined (47). Our study demonstrated that almost half of patients had positive CRP, but inconsistent with reports in adult COVID disease (48), CRP elevation was not associated with disease severity or death. Various mechanisms have been proposed for lymphopenia in COVID-19 patients, including direct effects of the virus on lymphocyte recruitment, destruction of lymphatic organs, and the presence of inflammatory cytokine storm (49). The results presented here are similar to previous studies $(21,35,50)$, and inconsistent with adults, as decreased lymphocytes cannot be considered a useful marker in pediatric COVID-19 patients. Common laboratory markers such as CRP and lymphopenia do not appear to be usable in the evaluation of severity of illness among children with COVID-19 disease; nevertheless, further investigations are needed to confirm the findings of this study.

Laterality, ground-glass opacity, and lung consolidation were the most common findings in chest CT. Serrano et al., reported that $90 \%$ of pediatric patients had ground-glass opacities (51). In contrast to a previous study from UK that reported no effusion (52), we found prevalence of pleural effusion among 2 patients. Due to the mild clinical manifestation in children during COVID-19, CT scan seems to be a more reliable method than chest X-ray. There is a concern about the increased risk of radiation exposure during CT scan that sometimes led to choosing other methods of imaging in children. Appropriate use of imaging and CT findings can improve early diagnosis and clinical management at different stages of the disease (53). The most common method for imaging to detect pneumonia in pediatrics with confirmed COVID-19 is the chest CT scan. Despite limitations due to the small number of CT findings, our 
results are in line with previous studies indicating that the chestCT can be a powerful method for investigation of pneumonia in pediatric COVID-19, even before the appearance of clinical symptoms (54). Like published literature in both children and adults, laterality and ground-glass opacity were our main finding, although with less extensive clinical manifestations compared with adults $(55,56)$.

It is well-accepted that SARS-CoV-2 can infect all individuals of any age. According to previous studies, activation and intensity of inflammatory cytokine cascades are the leading cause of death in older people with COVID-19 (7). Early in the pandemic, fatality and severity of illness were likely underestimated in children compared with adults, due to the low prevalence of severe infection and asymptomatic cases, and/or school closure and lockdown of child-care centers (57). There might have been little virus load in the airways, and presence of anti-inflammatory hormones like melatonin, and decreased expression of ACE2 and TMPRSS2 receptors in child airways (22). Although most children with positive SARS-Co-2 tests are asymptomatic or have mild clinical presentations, special attention should be given to children with comorbidities who may develop severe disease and MIS-C (58).

All hospitalized, pediatric COVID patients in this region were admitted to our hospital because this is the only pediatric hospital in the Golestan province. However, the low sample size is a limitation of this study. The limited number of children made adequate comparisons between age and gender impossible, as well as comparisons between some other subgroups. Further, the mortality rate was not consistent with previous studies in children with COVID-19; therefore more studies are needed to explore these issues in pediatric COVID disease.

\section{CONCLUSION}

A pandemic of COVID-19 is still ongoing worldwide, and contrary to previous perceptions, children have fallen victims in alarming numbers. Among children admitted to our hospital in northern Iran the main risk factor for death of COVID-19 disease was comorbidity. We may suggest radiologic proven laterality and ground-glass opacity and elevation of some biomarkers $(\mathrm{CPK}, \mathrm{LDH}$, and $\mathrm{PT})$ as potential indicators for severe disease or fatal outcome. Although few children were admitted to the hospital, the high death rate is worrying and should lead to

\section{REFERENCES}

1. Zhu N, Zhang D, Wang W, Li X, Yang B, Song J, et al. A novel coronavirus from patients with pneumonia in China, 2019. N Engl J Med. (2020) 382:72733. doi: 10.1056/NEJMoa2001017

2. World Health Organization. Naming the coronavirus disease (COVID-19) and the virus that causes it. Brazil J Implantol Health Sci. 2. Available online at: https://bjihs.emnuvens.com.br/bjihs/article/ view/173

3. Sharma A, Tiwari S, Deb MK, Marty JL. Severe acute respiratory syndrome coronavirus-2 (SARS-CoV-2): a global pandemic and treatment strategies. Int J Antimicrob Agents. (2020) 56:106054. doi: 10.1016/j.ijantimicag.2020. 106054 more comprehensive studies. Since we only included hospitalized cases and the number of patients was limited, this study may have overestimated patient mortality and morbidity rates. More studies on pediatric COVID disease are needed for an improved understanding of how and which children can develop a serious course. This may be preventive and predict which children may develop severe disease, and improve management and treatment of COVID-19 illness among individuals at greatest risk for severe disease and death.

\section{DATA AVAILABILITY STATEMENT}

The raw data supporting the conclusions of this article will be made available by the authors, without undue reservation.

\section{ETHICS STATEMENT}

The studies involving human participants were reviewed and approved by Ethics Committee of Golestan University of Medical Sciences (IR.GOUMS.REC.1400.142). Written informed consent to participate in this study was provided by the participants' legal guardian/next of kin.

\section{AUTHOR CONTRIBUTIONS}

ATah, MN, and FC conceptualized and designed the study, drafted the initial manuscript, and reviewed and revised the manuscript. ATah and $\mathrm{BN}$ designed the data collection instruments, coordinated and supervised data collection, and critically reviewed the manuscript. BA, LB, HN, and ATab collected data and reviewed and revised the manuscript. MG collected and reviewed the radiological images. BA and AR carried out the initial analyses and reviewed and revised the manuscript. All authors approved the final manuscript as submitted and agreed to be accountable for all aspects of the work.

\section{ACKNOWLEDGMENTS}

The authors would like to thank Golestan University of Medical Sciences and SARS-CoV-2 laboratory and nursing team that are fighting against the illness.

4. Teymoori-Rad M, Samadizadeh S, Tabarraei A, Moradi A, Shahbaz MB, Tahamtan A. Ten challenging questions about SARS-CoV-2 and COVID-19. Expert Rev Respir Med. (2020) 14:881-8. doi: 10.1080/17476348.2020.1782197

5. Jin Y, Yang H, Ji W, Wu W, Chen S, Zhang W, et al. Virology, epidemiology, pathogenesis, and control of COVID-19. Viruses. (2020) 12:372. doi: $10.3390 /$ v12040372

6. Tahamtan A, Samadizadeh S, Rastegar M, Nakstad B, Salimi V. Respiratory syncytial virus infection: why does disease severity vary among individuals? Expert Rev Respir Med. (2020) 14:415-23. doi: 10.1080/17476348.2020.1724095

7. Samadizadeh S, Masoudi M, Rastegar M, Salimi V, Shahbaz MB, Tahamtan A. COVID-19: Why does disease severity vary among individuals? Respir Med. (2021) 180:106356. doi: 10.1016/j.rmed.2021.106356 
8. Tahamtan A, Tavakoli-Yaraki M, Salimi V. Opioids/cannabinoids as a potential therapeutic approach in COVID-19 patients. Expert Rev Respir Med. (2020) 14:965-7. doi: 10.1080/17476348.2020.1787836

9. O'driscoll M, Dos Santos GR, Wang L, Cummings DA, Azman AS, Paireau J, et al. Age-specific mortality and immunity patterns of SARS-CoV-2. Nature. (2021) 590:140-5. doi: 10.1038/s41586-020-2918-0

10. Alsohime F, Temsah MH, Al-Nemri AM, Somily AM, Al-Subaie S. COVID-19 infection prevalence in pediatric population: Etiology, clinical presentation, and outcome. J Infect Public Health. (2020) 13:17916. doi: 10.1016/j.jiph.2020.10.008

11. Lin JE, Asfour A, Sewell TB, Hooe B, Pryce P, Earley C, et al. Neurological issues in children with COVID-19. Neurosci Lett. (2021) 743:135567. doi: 10.1016/j.neulet.2020.135567

12. Covid C, Team R, Covid C, Team R, Covid C, Team R, et al. Coronavirus disease 2019 in children-United States, february 12-april 2, 2020. Morbid Mortal Wkly Rep. (2020) 69:422. doi: 10.15585/mmwr.mm6914e4

13. Helms J, Kremer S, Merdji H, Clere-Jehl R, Schenck M, Kummerlen C, et al. Neurologic features in severe SARS-CoV-2 infection. $N$ Engl J Medicine. (2020) 382:2268-70. doi: 10.1056/NEJMc2008597

14. Mao L, Jin H, Wang M, Hu Y, Chen S, He Q, et al. Neurologic manifestations of hospitalized patients with coronavirus disease 2019 in Wuhan, China. JAMA Neurol. (2020) 77:683-90. doi: 10.1001/jamaneurol.2020.1127

15. Cheraghali F, Tahamtan A, Hosseini SA, Gharib MH, Moradi A, Razavi Nikoo $\mathrm{H}$, et al. Case report: detection of SARS-CoV-2 from cerebrospinal fluid in a 34-month-old child with encephalitis. Front Pediatrics. (2021) 9:194. doi: 10.3389/fped.2021.565778

16. Karimi A, Rafiei Tabatabaei S, Rajabnejad M, Pourmoghaddas Z, Rahimi H, Armin S, et al. An algorithmic approach to diagnosis and treatment of coronavirus disease 2019 (COVID-19) in children: Iranian expert's consensus statement. Arch Pediatric Infect Dis. (2020) 8:102400. doi: 10.5812/pedinfect. 102400

17. Soltani J, Sedighi I, Shalchi Z, Sami G, Moradveisi B, Nahidi S. Pediatric coronavirus disease 2019 (COVID-19): An insight from west of Iran. North Clin Istanbul. (2020) 7:284. doi: 10.14744/nci.2020.90277

18. Kiani M, Mohammadpour-Mir A, Sorkhi H, Esmaeili-Dooki M, Nikpour $\mathrm{M}$, Babazadeh K, et al. Multi-organ presentation of children with COVID19 infection in the north of Iran: a retrospective study. Int J Pediatr. (2021) 9:13411-9. doi: 10.22038/IJP.2020.51187.4065

19. Smith C, Odd D, Harwood R, Ward J, Linney M, Clark M, et al. Deaths in children and young people in England after SARS-CoV-2 infection during the first pandemic year. Nat Med. (2021). doi: 10.1038/s41591-02101578-1

20. Takahashi T, Ellingson MK, Wong P, Israelow B, Lucas C, Klein J, et al. Sex differences in immune responses that underlie COVID-19 disease outcomes. Nature. (2020) 588:315-20. doi: 10.1038/s41586-020-2700-3

21. Ludvigsson JF. Systematic review of COVID-19 in children shows milder cases and a better prognosis than adults. Acta Paediatr. (2020) 109:108895. doi: 10.1111/apa.15270

22. Zimmermann P, Curtis N. Why is COVID-19 less severe in children? A review of the proposed mechanisms underlying the age-related difference in severity of SARS-CoV-2 infections. Arch Dis Child. (2021) 106:42939. doi: 10.1136/archdischild-2020-320338

23. Shahbaznejad L, Rouhanizadeh H, Navaeifar MR, Hosseinzadeh F, Movahedi FS, Rezai MS. Clinical characteristics and outcomes of COVID-19 in children in northern Iran. Int J Pediatrics. (2021) 2021:5558287. doi: 10.1155/2021/5558287

24. Han X, Li X, Xiao Y, Yang R, Wang $Y$, Wei X. Distinct characteristics of COVID-19 infection in children. Front Pediatrics. (2021) 9:130. doi: $10.3389 /$ fped.2021.6 19738

25. Chen N, Zhou M, Dong X, Qu J, Gong F, Han Y, et al. Epidemiological and clinical characteristics of 99 cases of 2019 novel coronavirus pneumonia in Wuhan, China: a descriptive study. Lancet. (2020) 395:507-13. doi: 10.1016/S0140-6736(20)30211-7

26. Huang C, Wang Y, Li X, Ren L, Zhao J, Hu Y, et al. Clinical features of patients infected with 2019 novel coronavirus in Wuhan, China. Lancet. (2020) 395:497-506. doi: 10.1016/S0140-6736(20) 30183-5
27. Guan W-J, Ni Z-Y, Hu Y, Liang W-H, Ou C-Q, He J-X, et al. Clinical characteristics of coronavirus disease 2019 in China. N Engl J Medicine. (2020) 382:1708-20. doi: 10.1056/NEJMoa2002032

28. Duramaz BB, Yozgat CY, Yozgat Y, Turel O. Appearance of skin rash in pediatric patients with COVID-19: three case presentations. Dermatol Ther. (2020) 33:e13594. doi: 10.1055/a-1263-1222

29. Tsankov BK, Allaire JM, Irvine MA, Lopez AA, Sauvé LJ, Vallance BA, et al. Severe COVID-19 infection and pediatric comorbidities: a systematic review and meta-analysis. Int J Infect Dis. (2020) 103:24656. doi: 10.1016/j.ijid.2020.11.163

30. Cheraghali F, Barati L, Amanian D, Shahkar L, Najafinejad M, Naziri H, et al. A case series of pediatric COVID-19 with complicated symptoms in Iran. Future Virol. (2021) 16:649-56. doi: 10.2217/fvl-2021-0091

31. Ogimi C, Englund JA, Bradford MC, Qin X, Boeckh M, Waghmare A. Characteristics and outcomes of coronavirus infection in children: the role of viral factors and an immunocompromised state. J Pediatric Infect Dis Soc. (2019) 8:21-8. doi: 10.1093/jpids/pix093

32. Remppis J, Ganzenmueller T, Vasconcelos MK, Heinzel O, Handgretinger R, Renk H. A case series of children and young people admitted to a tertiary care hospital in Germany with COVID-19. BMC Infect Dis. (2021) 21:1-6. doi: 10.1186/s12879-021-05791-8

33. Papoutsi E, Giannakoulis VG, Xourgia E, Routsi C, Kotanidou A, Siempos II. Effect of timing of intubation on clinical outcomes of critically ill patients with COVID-19: a systematic review and meta-analysis of non-randomized cohort studies. Critical Care. (2021) 25:1-9. doi: 10.1186/s13054-021-03540-6

34. Siempos II, Xourgia E, Ntaidou TK, Zervakis D, Magira EE, Kotanidou A, et al. Effect of early vs. delayed or no intubation on clinical outcomes of patients with COVID-19: an observational study. Front Med. (2020) 7:614152. doi: 10.3389/fmed.2020.614152

35. Qiu H, Wu J, Hong L, Luo Y, Song Q, Chen D. Clinical and epidemiological features of 36 children with coronavirus disease 2019 (COVID-19) in Zhejiang, China: an observational cohort study. Lancet Infect Dis. (2020) 20:689-96. doi: 10.1016/S1473-3099(20)30198-5

36. Hasan SS, Capstick T, Ahmed R, Kow CS, Mazhar F, Merchant HA, et al. Mortality in COVID-19 patients with acute respiratory distress syndrome and corticosteroids use: a systematic review and meta-analysis. Expert Rev Respir Med. (2020) 14:1149-63. doi: 10.1080/17476348.2020.1804365

37. Khoshnood RJ, Ommi D, Zali A, Ashrafi F, Vahidi M, Azhide A, et al. Epidemiological characteristics, clinical features, and outcome of COVID-19 patients in northern Tehran, Iran; a cross-sectional study. Adv J Emerg Med. (2020) 127:104378. doi: 10.1016/j.jcv.2020.104378

38. Rees EM, Nightingale ES, Jafari Y, Waterlow NR, Clifford S, Pearson CA, et al. COVID-19 length of hospital stay: a systematic review and data synthesis. BMC Med. (2020) 18:1-22. doi: 10.1186/s12916-020-01726-3

39. World Health Organization. COVID-19 Clinical Management: Living Guidance, 25 January 2021. Geneva: World Health Organization (2021).

40. Araya S, Mamo MA, Tsegay YG, Atlaw A, Aytenew A, Hordofa A, et al. Blood coagulation parameter abnormalities in hospitalized patients with confirmed COVID-19 in Ethiopia. PLoS ONE. (2021) 16:e0252939. doi: 10.1371/journal.pone.0252939

41. Saleh M, Alkofide A, Alshammari A, Siddiqui K, Owaidah T. Changes in hematological, clinical and laboratory parameters for children with COVID-19: single-center experience. J Blood Med. (2021) 12:819. doi: 10.2147/JBM.S321372

42. Henry BM, De Oliveira MHS, Benoit S, Plebani M, Lippi G. Hematologic, biochemical and immune biomarker abnormalities associated with severe illness and mortality in coronavirus disease 2019 (COVID-19): a metaanalysis. Clin Chem Lab Med. (2020) 58:1021-8. doi: 10.1515/cclm-2020-0369

43. Parohan M, Yaghoubi S, Seraji A. Liver injury is associated with severe coronavirus disease 2019 (COVID-19) infection: a systematic review and meta-analysis of retrospective studies. Hepatol Res. (2020) 50:92435. doi: 10.1111/hepr.13510

44. Akbar MR, Pranata R, Wibowo A, Lim MA, Sihite TA, Martha JW. The prognostic value of elevated creatine kinase to predict poor outcome in patients with COVID-19-a systematic review and meta-analysis. Diab Metab Syndr. (2021) 15:529-34. doi: 10.1016/j.dsx.2021.02.012

45. De Rosa A, Verrengia EP, Merlo I, Rea F, Siciliano G, Corrao G, et al. Muscle manifestations and CK levels in COVID infection: results of a large 
cohort of patients inside a Pandemic COVID-19 Area. Acta Myol. (2021) 40:1. doi: 10.21203/rs.3.rs-98470/v1

46. Henry BM, Aggarwal G, Wong J, Benoit S, Vikse J, Plebani M, et al. Lactate dehydrogenase levels predict coronavirus disease 2019 (COVID-19) severity and mortality: a pooled analysis. Am J Emerg Med. (2020) 38:17226. doi: 10.1016/j.ajem.2020.05.073

47. Wu P, Hao X, Lau EH, Wong JY, Leung KS, Wu JT, et al. Real-time tentative assessment of the epidemiological characteristics of novel coronavirus infections in Wuhan, China, as at 22 January 2020. Eurosurveillance. (2020) 25:2000044. doi: 10.2807/1560-7917.ES.2020.25.3.2000044

48. Li X, Wang L, Yan S, Yang F, Xiang L, Zhu J, et al. Clinical characteristics of 25 death cases with COVID-19: a retrospective review of medical records in a single medical center, Wuhan, China. Int J Infect Dis. (2020) 94:12832. doi: 10.1016/j.ijid.2020.03.053

49. Tan L, Wang Q, Zhang D, Ding J, Huang Q, Tang Y-Q, et al. Lymphopenia predicts disease severity of COVID-19: a descriptive and predictive study. Signal Transduct Target Ther. (2020) 5:1-3. doi: 10.1038/s41392-020-0159-1

50. Mamishi S, Movahedi Z, Mohammadi M, Ziaee V, Khodabandeh M, Abdolsalehi MR, et al. Multisystem inflammatory syndrome associated with SARS-CoV-2 infection in 45 children: a first report from Iran. Epidemiol Inf. (2020) 148:e196. doi: 10.1017/S095026882000196X

51. Serrano CO, Alonso E, Andrés M, Buitrago N, Vigara AP, Pajares MP, et al. Pediatric chest X-ray in covid-19 infection. Eur J Radiol. (2020) 131:109236. doi: 10.1016/j.ejrad.2020.109236

52. Palabiyik F, Kokurcan SO, Hatipoglu N, Cebeci SO, Inci E. Imaging of COVID-19 pneumonia in children. $\mathrm{Br} J$ Radiol. (2020) 93:20200647. doi: 10.1259/bjr.20200647

53. Liguoro I, Pilotto C, Bonanni M, Ferrari ME, Pusiol A, Nocerino A, et al. SARS-COV-2 infection in children and newborns: a systematic review. Eur J Pediatr. (2020) 179:1029-46. doi: 10.1007/s00431-020-03684-7

54. Kumar J, Meena J, Yadav A, Yadav J. Radiological findings of COVID-19 in children: a systematic review and meta-analysis. J Trop Pediatrics. (2021) 67:fmaa045. doi: 10.1093/tropej/fmaa045
55. Steinberger S, Lin B, Bernheim A, Chung M, Gao Y, Xie Z, et al. CT features of coronavirus disease (COVID-19) in 30 pediatric patients. Am J Roentgenol. (2020) 215:1303-11. doi: 10.2214/AJR.20. 23145

56. Sun Z, Zhang $\mathrm{N}$, Li $\mathrm{Y}$, Xu X. A systematic review of chest imaging findings in COVID-19. Quant Imaging Med Surg. (2020) 10:1058. doi: 10.21037/qims-20-564

57. Davies NG, Klepac P, Liu Y, Prem K, Jit M, Eggo RM. Age-dependent effects in the transmission and control of COVID-19 epidemics. Nat Med. (2020) 26:1205-11. doi: 10.1038/s41591-020-0962-9

58. Mcnally VV, Bernstein HH. The effect of the COVID-19 pandemic on childhood immunizations: ways to strengthen routine vaccination. Pediatr Ann. (2020) 49:e516-22. doi: 10.3928/1938235920201115-01

Conflict of Interest: The authors declare that the research was conducted in the absence of any commercial or financial relationships that could be construed as a potential conflict of interest.

Publisher's Note: All claims expressed in this article are solely those of the authors and do not necessarily represent those of their affiliated organizations, or those of the publisher, the editors and the reviewers. Any product that may be evaluated in this article, or claim that may be made by its manufacturer, is not guaranteed or endorsed by the publisher.

Copyright $\odot 2022$ Najafinejad, Cheraghali, Aghcheli, Rajabi, Barati, Naziri, Gharib, Tabarraei, Nakstad and Tahamtan. This is an open-access article distributed under the terms of the Creative Commons Attribution License (CC BY). The use, distribution or reproduction in other forums is permitted, provided the original author(s) and the copyright owner(s) are credited and that the original publication in this journal is cited, in accordance with accepted academic practice. No use, distribution or reproduction is permitted which does not comply with these terms. 